\title{
Thermal Characterization of Poly(vinyl chloride) Samples Prepared by Living Radical Polymerization: Comparison with Poly(vinyl chloride) Prepared by Free Radical Polymerization
}

\author{
Jorge F. J. Coelho, ${ }^{1,2}$ P. N. Simões, ${ }^{1}$ Patrícia V. Mendonça, ${ }^{1}$ A. C. Fonseca, ${ }^{1}$ M. H. Gil ${ }^{1}$ \\ ${ }^{1}$ Department of Chemical Engineering, University of Coimbra, 3030-290 Coimbra, Portugal \\ ${ }^{2}$ Centre of Opthalmology, Biomedical Institute for Research in Light and Image (IBILI), Faculty of Medicine, \\ University of Coimbra, 3000-354 Coimbra, Portugal
}

Received 14 December 2007; accepted 26 February 2008

DOI 10.1002/app.28318

Published online 12 May 2008 in Wiley InterScience (www.interscience.wiley.com).

\begin{abstract}
Poly(vinyl chloride) (PVC) samples were synthesized by a living radical polymerization (LRP) method and compared with commercial PVC prepared by the conventional free radical polymerization (FRP). The differences were assessed, for the first time, in terms of viscosimetry parameters and thermal analysis. The LRP method used to prepare the PVC-LRP samples is the only one available to obtain this polymer free of structural defects, being of commercial interest in a view of preparing a new generation of PVC-based polymer with outstanding performance. The polymerization temperature selected $\left(35^{\circ} \mathrm{C}\right)$ to prepare the LRP samples is currently used in the industry to prepare PVC-FRP grades with moderate to high molecular weight. Since the thermal sta-
\end{abstract}

bility is a direct consequence of the polymer structure, this study is of vital importance to understand the potential of new PVC-LRP. The thermoanalytical measurements demonstrate an enhanced thermal stability of PVC-LRP when compared with its FRP counterpart. The PVC-LRP sample with very low molecular weight reveals a higher thermal stability than the most stable PVC-FRP sample. It is the first report dealing with thermal analysis of PVC prepared by LRP. (C) 2008 Wiley Periodicals, Inc. J Appl Polym Sci 109: 2729-2736, 2008

Key words: poly(vinyl chloride); living radical polymerization; free radical polymerization; thermal analysis; thermal stability

\section{INTRODUCTION}

Living radical polymerization (LRP) represents an effective route to synthesize polymers with controlled structure, morphology, functionality, and architecture. Since the middle of the 1990s, the LRP received huge attention from the academia and industrial world. Several major mechanisms have been reported in the literature via metal-catalyzed LRP, ${ }^{1,2}$ nitroxide-mediated polymerization (NMP), ${ }^{3}$ stable free radical polymerization (SFRP), ${ }^{4}$ and reversible addition-fragmentation chain transfer (RAFT) ${ }^{5}$ Nevertheless, the stringent conditions associated to some of these methods have limited the perspectives for widespread of commercial products. After several years of the development, Percec et al. discovered a new strategy to polymerize-activated ${ }^{6-8}$ and nonactivated monomers, ${ }^{9-11}$ under controlled/ living mechanism in aqueous medium. In addition, this method requires only industrially consumed compounds and lead to a polymer that does not need to be purified. This new method was called

Correspondence to: J. F. J. Coelho (jcoelho3@gmail.com).

Journal of Applied Polymer Science, Vol. 109, 2729-2736 (2008) (C) 2008 Wiley Periodicals, Inc. single electron transfer-degenerative chain transfer mediated living radical polymerization (SET-DTLRP). It provides the reversible activation-deactivation step required to accomplish LRP by the combination of competitive single-electron-transfer (SET) and degenerative-chain transfer (DT). ${ }^{10}$ The SET-DTLRP allows the synthesis of PVC free of internal allyl and tertiary alkyl chloride structural defects, which result from inevitable side reactions that are present in the FRP process. Apart form that, the use of iodoform allows each polymer chains to grow in two directions at the same time. Because sodium dithionate is not able to form growing radicals and start the polymerization, as happens for example when peroxides are used (common DCT systems), a better control over the polymerization is achieved. The outstanding structural properties of the PVC that resulted from this LRP method were already assessed by nuclear magnetic resonance ${ }^{10}$ (NMR) carried out to very lowmolecular weight PVC samples that could not be prepared without a living mechanism. The new PVCLRP prepared by SET-DTLRP demonstrated to have high crystallinity, ${ }^{10}$ to be free of structural defects, ${ }^{9,10}$ and to require more than twice the time to burn completely in the discoloration tests by using the standard discoloration tests used in the industry. ${ }^{12}$ Apart 
from the enhanced properties, the PVC-LRP has active chain ends that can be functionalized or reinitiated leading to new properties that widens the range of application of this polymer. ${ }^{13,14}$

Because of its technological relevance and scientific importance, the thermal degradation and stabilization mechanism of PVC has been the subject of various studies and reviews. ${ }^{15,16}$ The internal allylic chloride and tertiary chloride structural defects that are formed during the polymerization are identified as being structures responsible for the beginning of the dehydrochlorination process. Despite the low concentration in the PVC chains (allyl chloride concentration of 0.9 per molecule ${ }^{17}$ ), the structural defects are responsible for the thermal dehydrochlorination process. In terms of tertiary chlorides, PVC chains prepared at temperatures between 40 and $82^{\circ} \mathrm{C}$ have between 1.0 and 2,4-dichloro- $n$-butyl branches per 1000 monomer units. ${ }^{18}$ It is known that the thermal stability of the PVC is a direct consequence of the structural defects concentration, which are expected to be residual in the PVC-LRP. This result is obtained by the conjunction of the following effects: low reaction temperatures; a much lower amount of growing radicals when compared with the FRP process, which are in a fast exchange with their iodine encapped dormant species. This exchange occurs because of the nature of those PVC particles as a consequence of electron effects (mesorimeric and inductive). ${ }^{9}$

Several attempts to prepare PVC macrostructures free of structural defects can be found in the literature. ${ }^{19-22}$ However, to the best of our knowledge, the SET-DTLRP is the only method that allows the synthesis of the PVC without this unwanted structures. In this article, we report the first study on the degradation behavior of PVC prepared by SET-DTLRP and the comparison with the results obtained with the commercial PVC prepared by FRP. This work is important to evaluate the effective difference of the PVC prepared by FRP and LRP in terms of structure and thermal stability, which are actual keys properties for the PVC business.

\section{EXPERIMENTAL}

\section{Materials}

The tetrahydrofuran HPLC-grade uninhibited, sand, alumina oxide, iodoform $\left(\mathrm{CHI}_{3}\right)(99 \%)$, sodium dithionite $\left(\mathrm{Na}_{2} \mathrm{~S}_{2} \mathrm{O}_{4}\right)(85 \%)$, and sodium bicarbonate $\left(\mathrm{NaHCO}_{3}\right)(99 \%)$ were ordered from Sigma-Aldrich (Sintra, Portugal). The polystyrene standards were purchased from Polymer Laboratories. The PVC standard was purchased from Sigma Aldrich and used as received. The Methocel F50 was ordered from Dow Chemical Company (Barcelona, Spain). The PVA $\left(M_{w} 85,000-124,000,87-89 \%\right.$ hydrolyzed $)$ was purchased from Sigma-Aldrich. The antifouling agent made of poly(aryl phenols) Noxol WSW was supplied by Akzo Nobel (Barcelona, Spain). The silicone-based antifoaming agent and vinyl chloride were supplied by Shin-Etsu (Rotterdam, The Netherlands). The PVC-FRP samples were kindly supplied by CIRES SA.

\section{Synthesis of PVC-LRP at $35^{\circ} \mathrm{C}$}

In a typical experiment, a 50-mL Ace Glass 8648 \#15 Ace-Thred pressure tube equipped with bushing and plunger valve was charged with a previously degassed $9 \mathrm{~mL}$ mixture of deionized water and $222.6 \mathrm{mg}$ of $1.86 \%$ water solution of Methocel F50 and $322.1 \mathrm{mg}$ of $3 \%$ water solution of PVA 88 ([Methocel F50] : [PVA 88] $=840 \mathrm{ppm}: 1960 \mathrm{ppm} \mathrm{w} / \mathrm{w}$ relative to VCM). The tube was filled with argon, closed and frozen in $\mathrm{MeOH} /$ dry ice. Then, the initiator $\left(\mathrm{CHI}_{3}\right.$, $31.1 \mathrm{mg}, 0.080 \mathrm{mmol})$, catalyst $\left(\mathrm{Na}_{2} \mathrm{~S}_{2} \mathrm{O}_{4}\right), 54.9 \mathrm{mg}$, $0.321 \mathrm{mmol})$, buffer $\left(\mathrm{NaHCO}_{3}, 13.25 \mathrm{mg}, 0.160\right.$ $\mathrm{mmol})$, and precondensed VCM (3 $\mathrm{mL}, 0.043 \mathrm{~mol})$ were added. The exact amount of VCM was determined gravimetrically. The tube was closed and degassed through the plunger valve by applying reduced pressure and filling the tube with nitrogen 15 times at $40^{\circ} \mathrm{C}$. The valve was closed and the reaction mixture was stirred in a water bath at $35^{\circ} \mathrm{C} \pm$ $0.5^{\circ} \mathrm{C}$ behind a protective shield. After $46 \mathrm{~h}$, the tube was slowly opened, the excess of VCM was allowed to evaporate and the mixture was poured into deionized water $(100 \mathrm{~mL})$. The polymer separated was accomplished by filtration, rinsed twice with $30 \mathrm{~mL}$ of deionized water, and dried in a vacuum oven to constant weight to give $1.90 \mathrm{~g}(63 \%)$ of PVC. The different quantities used for the three PVC-LRP samples prepared are summarized in Table I.

\section{Sample preparation for size exclusion chromatography}

The procedure followed to prepare the samples for TriSEC analysis is described elsewhere. ${ }^{23}$

\section{Characterization techniques}

The chromatography parameters of the samples were determined using a HPSEC-Viscotek (Dual detector 270, Viscotek, Houston) with a differential viscometry (DV), right angle laser light-scattering (RALLS, Viscotek), and RI (Knauer K-2301). The column set consisted of a PL 10- $\mu \mathrm{m}$ guard column $(50 \mathrm{~mm} \times 7.5 \mathrm{~mm})$ followed by two MIXED-B PL columns $(300 \mathrm{~mm} \times 7.5 \mathrm{~mm}, 10 \mu \mathrm{m})$. HPLC pump (Knauer K-1001) with a flow rate of $1 \mathrm{~mL} \mathrm{~min}^{-1}$. The eluent was previously filtered through a $0.2-\mu \mathrm{m}$ filter. The system is also equipped with a Knauer on-line degasser. The tests were done at $30^{\circ} \mathrm{C}$ using an Elder CH-150 heater. Before the injection $(100 \mu \mathrm{L})$, 
TABLE I

Experimental Conditions Used to Prepare the PVC-LRP Samples

\begin{tabular}{lcccccccc}
\hline Sample & $\begin{array}{c}\mathrm{VCM} \\
(\mathrm{mmol})\end{array}$ & $\begin{array}{c}\mathrm{CHI}_{3} \\
(\mathrm{mmol})\end{array}$ & $\begin{array}{c}\mathrm{Na}_{2} \mathrm{~S}_{2} \mathrm{O}_{4} \\
(\mathrm{mmol})\end{array}$ & $\begin{array}{c}\mathrm{NaHCO}_{3} \\
(\mathrm{mmol})\end{array}$ & $\begin{array}{c}\text { MF50 } \\
(\mathrm{mmol})\end{array}$ & $\begin{array}{c}\text { PVA88 } \\
(\mathrm{mmol})\end{array}$ & $\begin{array}{c}\text { Time } \\
(\mathrm{h})\end{array}$ & $\begin{array}{c}\text { Conv } \\
(\%)\end{array}$ \\
\hline LRPL & 43.68 & 0.080 & 0.321 & 0.160 & 840 & 1,960 & 46 & 63 \\
LRPM & 43.68 & 0.023 & 0.092 & 0.046 & 840 & 1,960 & 46 & 40 \\
LRPH & 43.68 & 0.011 & 0.044 & 0.022 & 840 & 1,960 & 46 & 42 \\
\hline
\end{tabular}

the samples were filtered through a PTFE membrane with $0.2 \mu \mathrm{m}$. The system was calibrated with narrow polystyrene standards. The differential refractive index $(d n / d c)$ for $670 \mathrm{~nm}$ was determined by using the Viscotek Software $3.0(d n / d c=0.105)$. The analysis of light scattering data by Viscotek's software (OmniSEC 3.0) were done assuming the second virial coefficient was zero, considering the low solution concentrations used in this work.

Simultaneous heat-flux differential scanning calorimetry (DSC) and thermogravimetry (TG) was employed to investigate the thermal decomposition behavior of the polymeric samples in nonisothermal conditions, focusing the dehydrochlorination step. The measurements were carried out using TA Instruments SDT Q600 equipment (thermobalance sensitivity: $0.1 \mu \mathrm{g})$. Alumina crucibles were employed. The calibration was performed in the range $25-1000^{\circ} \mathrm{C}$ by running tin and lead as melting standards.

This procedure was performed for each heating rate values used throughout the experimental work (2 and $20^{\circ} \mathrm{C} \mathrm{min}^{-1}$ ). Powdered PVC samples were loaded into open alumina crucibles, and a dry nitrogen purge flow of $100 \mathrm{~mL} \mathrm{~min}^{-1}$ was used in all the measurements. Sample weights ranging from $\sim 4$ to $6 \mathrm{mg}$ were used (variation in sample weight showed no significant influence on the thermoanalytical curves). At least two runs have been performed for each sample to check the repeatability of measurements.

\section{K-value determination}

Two PVC samples of $0.250 \pm 0.002 \mathrm{~g}$ were weighted and added to $100-\mathrm{mL}$ volumetric flasks. The flasks were filled with cyclohexanone until 2/3 of the volume and carefully stirred in a temperature-controlled glycerin heating bath at $85^{\circ} \mathrm{C} \pm 5^{\circ} \mathrm{C}$ until complete dissolution. After that, the solutions were allowed to cool down to room temperature. The flasks were then filled completely with cyclohexanone preheated at $85^{\circ} \mathrm{C} \pm 5^{\circ} \mathrm{C}$ during $90 \mathrm{~min}$, and placed in isotherm bath at $30^{\circ} \mathrm{C} \pm 0.5^{\circ} \mathrm{C}$ for $20 \mathrm{~min}$. The volume of cyclohexanone was readjusted with solvent at $30^{\circ} \mathrm{C} \pm 0.5^{\circ} \mathrm{C}$. The samples were then stirred until complete dissolution and filtered through a porous plaque G-1. Using an AVS 50 viscometer, the time constant for the solvent $\left(t_{0}\right)$ and the samples were determined $(t)$. To validate the sample measurements, three determinations were carried out for each sample considering that the maximum difference could not exceed $0.1 \%$. The methodology described here results from the adjustment of the standard procedure DIN 53726.

\section{RESULTS AND DISCUSSION}

\section{Molecular weight and viscosimetric determinations}

The molecular weight distributions were determined by using a multidetector size exclusion chromatography (TriSEC). Polystyrene (PS) and PVC standards were used to determine the results quality provided by the equipment in the molecular weight determination of the PVC samples. (Table II ).

The PVC samples were exposed to an ultrasonic treatment during $30 \mathrm{~min}$ to break down the PVC aggregates in THF following a method developed in the same laboratory. ${ }^{23}$ Table III shows the results obtained for the different samples studied and its relation with terminology used in the industry. In addition, the equipment apparatus using the calibration with PS66350 standard led to the same MW provided by the supplied for the PVC sample. Figure 1 shows the quality of the chromatograms obtained for

TABLE II

Molecular Weights of the Standards

\begin{tabular}{lcccccrr}
\hline Standard & $\begin{array}{c}M_{w}(\mathrm{Da}) \\
(\text { supplier })\end{array}$ & $\begin{array}{c}M_{w}(\mathrm{Da}) \\
(\text { obtained })\end{array}$ & $\begin{array}{c}\text { Error } \\
(\%)\end{array}$ & $M_{w} / M_{n}$ & $\begin{array}{c}\eta \\
(\mathrm{dL} / \mathrm{g})\end{array}$ & $\begin{array}{c}R_{g} \\
(\mathrm{~nm})\end{array}$ & $\begin{array}{r}R_{h} \\
(\mathrm{~nm})\end{array}$ \\
\hline PS19880 & 19,880 & 19,516 & 1.8 & 1.03 & 0.166 & 4.84 & 3.66 \\
PS630000 & 630,000 & 626,111 & 0.9 & 1.01 & 2.020 & 35.24 & 27.55 \\
PVC36000 & 36,000 & 37,313 & 1.9 & 1.20 & 0.485 & 8.30 & 6.43 \\
\hline
\end{tabular}


TABLE III

Molecular Weight Averages, Hydrodynamic Parameters, and K Value for the PVC Samples Analyzed in This Work

\begin{tabular}{|c|c|c|c|c|c|c|c|c|c|c|}
\hline Sample & $\begin{array}{c}M_{n}, \text { TriSEC } \\
\text { (Da) }\end{array}$ & $\begin{array}{c}M_{w}, \text { TriSEC } \\
\text { (Da) }\end{array}$ & $\begin{array}{c}M_{w} / M_{n} \\
(\mathrm{Da})\end{array}$ & $\begin{array}{c}\eta \\
(\mathrm{dL} / \mathrm{g})\end{array}$ & $\begin{array}{c}R_{h} \\
(\mathrm{~nm})\end{array}$ & $\begin{array}{c}R_{g} \\
(\mathrm{~nm})\end{array}$ & $K$ value & Method & $\begin{array}{c}\text { Temp } \\
\left({ }^{\circ} \mathrm{C}\right)\end{array}$ & $\begin{array}{c}\text { Conversion } \\
(\%)\end{array}$ \\
\hline FRPL & 37,473 & 61,546 & 1.64 & 0.774 & 8.660 & 11.299 & 55 & FRP & 63 & 72 \\
\hline FRPM & 62,350 & 102,847 & 1.65 & 1.149 & 11.710 & 15.260 & 66 & FRP & 56 & 70 \\
\hline FRPH & 91,041 & 155,251 & 1.70 & 1.534 & 14.729 & 19.248 & 79 & FRP & 44 & 74 \\
\hline LRPL & 20,050 & 34,085 & 1.74 & 0.424 & 4.256 & 5.532 & 44 & LRP & 35 & 65 \\
\hline LRPM & 64,926 & 114,460 & 1.76 & 1.052 & 11.824 & 15.451 & 70 & LRP & 35 & 68 \\
\hline LRPH & 99,663 & 184,841 & 1.85 & 1.503 & 15.309 & 20.005 & 86 & LRP & 35 & 71 \\
\hline
\end{tabular}

the PVC-LRP samples. The same result was observed for the PVC-FRP samples.

Figure 2 presents the RI traces obtained for the different samples studied.

The RI traces shown in Figure 2 suggest the absence of important macrostructural differences due to the similar monomodal curve shapes.

Table III summarizes the results obtained for the different PVC samples studied. From Table III, it is possible to verify that the PVC samples prepared for this study have the same range of molecular weight. Additionally, the PVC-LRP samples show the possibility of synthesizing PVC samples with molecular weight as low as $20 \mathrm{kDa}$ at $35^{\circ} \mathrm{C}$. This is an additional proof of the presence of a living method, in which the molecular weight is controlled by the ratio monomer/initiator and not the reaction temperature. In fact, such low molecular weight would be impossible to be achieved by FRP considering the reaction temperature used. In terms of polydispersity, the values registered for the PVC-LRP samples are outside the typical values that could be expected from a living system. The reasons behind these values are already discussed in a previous publication ${ }^{24}$ and thus are not exposed here again.

The dependence of the limit number of viscosity determined using the viscometer of the TriSEC detector and the molecular weight for the samples with higher molecular weight prepared by FRP and LRP are indicated in Figure 3. The results suggest that in the range of middle molecular weight, the PVC prepared by FRP has higher viscosity than the PVC-LRP. This result is not obvious since higher linearity (PVC-LRP) results in higher viscosity for the same molecular weight because of higher interactions between the polymer chains. Based on that, other effects may contribute to this result and need to be addressed in future studies. Nevertheless, the PVC-LRP presents higher viscosity for the HMW fractions. It is known that chain transfer reactions resulting from previous head-to-head additions determine the final molecular weight of the PVC prepared by FRP. In Figure 3, it is possible to observe that decrease of viscosity due to side chains become more pronounced for the higher molecular weight fractions. The results presented in Figure 3 suggest the existence of a molecular weight value from which the viscosity of the PVC-LRP becomes much higher than the viscosity of the PVC-FRP for the same molecular weight. Since the PVC samples are not monodisperse, for a certain value $M_{n}$ of some LMW fractions and HMW fractions are detected. Thus, it is normal for major differences found in the HMW fractions, because the surface area available for interaction is greater. Moreover, the PVC-LRP sample shows a perfect linear dependence of the viscosity versus molecular weight in the whole range of molecular weight of the calibration file. Another important feature of the SET-DTLRP is the relatively low conversions obtained when compared with the FRP process. The monomer concentration is known to have an important effect on the occurrence of side reactions. The decrease in the monomer concentration leads to an increase in the number of side reactions.

The dependence of the radius of gyration $\left(R_{g}\right.$, which describes a mathematical radius based on the average distance of mass components of the molecule from its center of mass) with the molecular weight is plotted in Figure 4.

As expected, the $R_{g}$ values obtained for the polymers prepared by both methods are typical of a random coil conformation. ${ }^{23}$ In accordance with Figure 3,

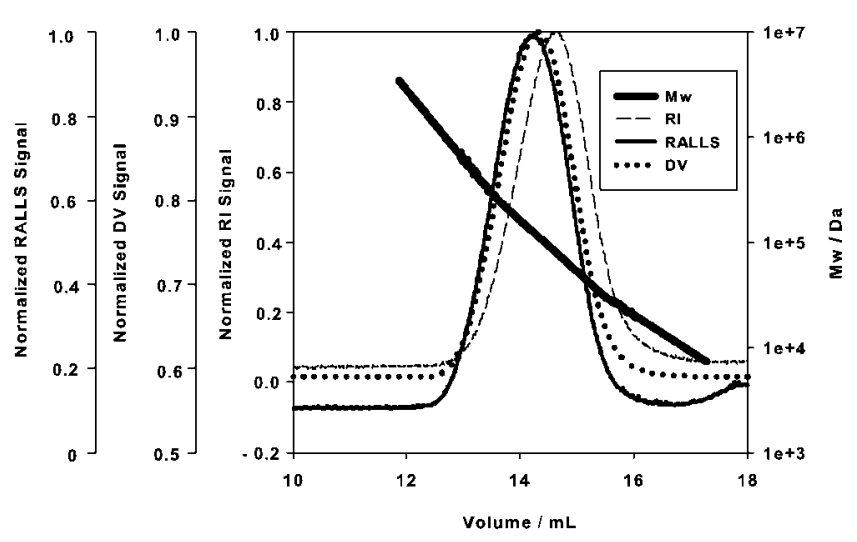

Figure 1 TriSEC chromatogram for the sample PVC samples prepared by LRPL after $30 \mathrm{~min}$ of ultrasonic treatment. 


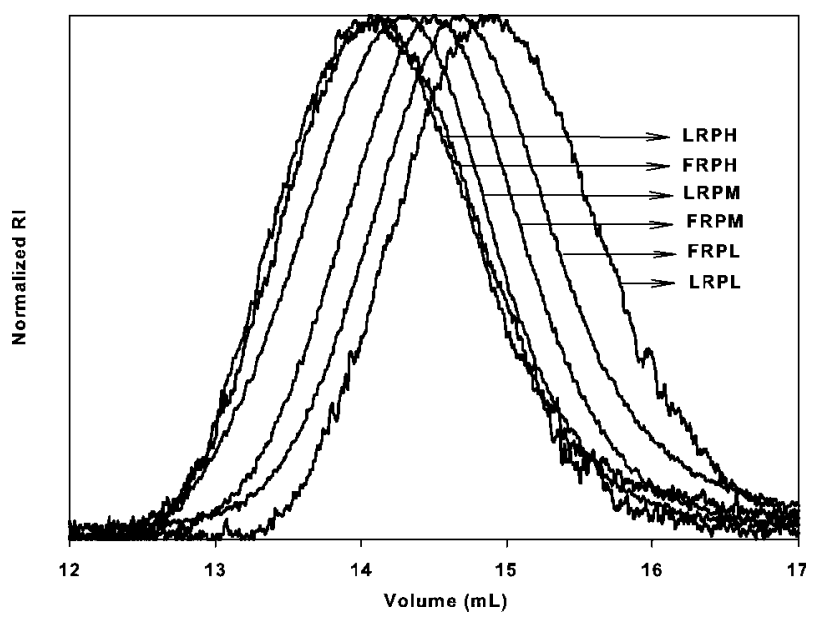

Figure 2 RI traces of the PVC samples.

the differences observed between both polymerization methods are very low. The results presented in Figures 3 and 4 are very interesting since the molecular weight of both samples is practically the same. Again, the sample prepared by LRP exhibits a linear evolution of the $R_{g}$ in the whole range of molecular weight considered.

\section{Thermoanalytical results}

The development of new polymerization strategies that allow the control over the macrostructure and microstructure of the polymeric materials prepared by radical methods turn possible the preparation of old material with new properties. The VCM radical polymerization is known to be accompanied by side reactions ${ }^{10}$ that induce the appearance of unwanted structures known as structural defects. The number

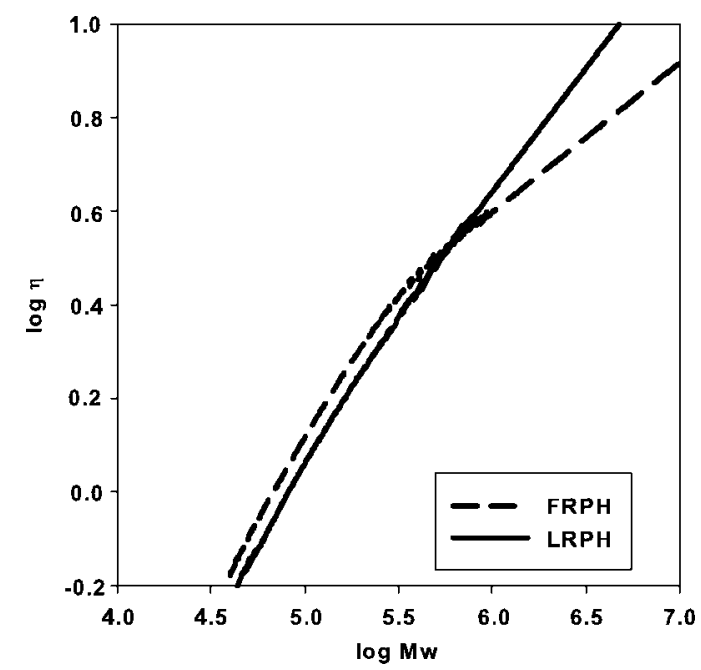

Figure 3 Molecular weight versus intrinsic viscosity of samples FRPH and LRPH.

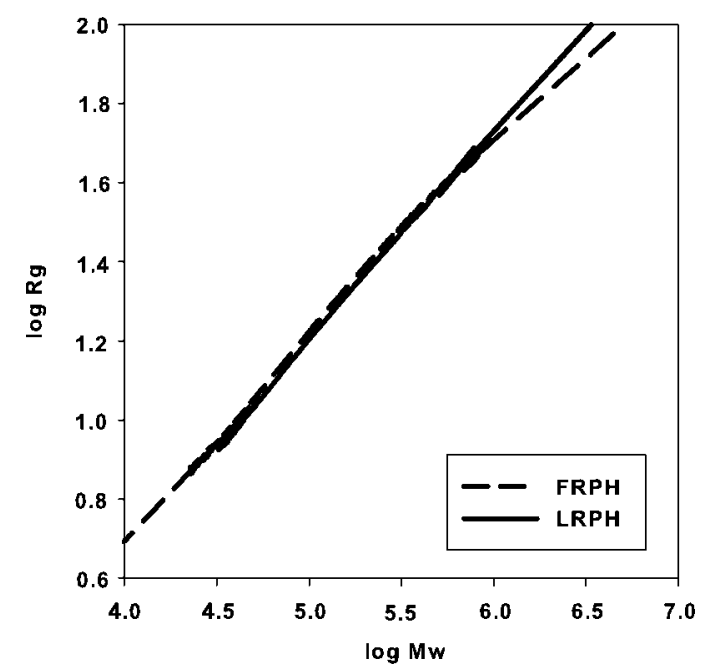

Figure 4 Radius of gyration versus intrinsic viscosity of samples FRPH and LRPH.

and frequency of these structures dictates the thermal stability of the PVC. In the conventional free radical polymerization, the molecular weight is completely controlled by the reaction temperature, being almost independent of the initiator concentration. ${ }^{25,26}$ Higher polymerization temperatures lead to higher
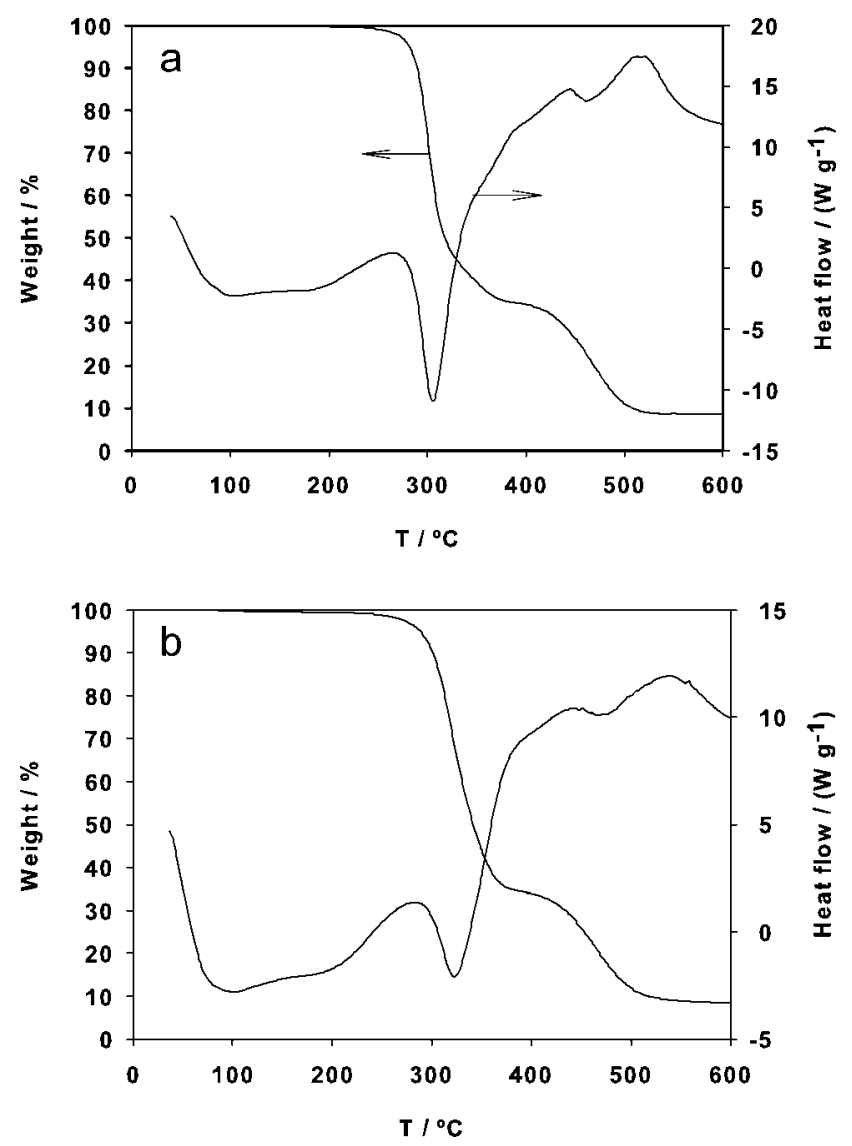

Figure 5 Typical thermoanalytical curves at $20^{\circ} \mathrm{C} \mathrm{min} \mathrm{min}^{-1}$ for the indicated samples: (a) LRPH and (b) FRPH. 
TABLE IV

Extrapolated Onset Temperatures $\left(T_{\text {on }}\right.$ in $\left.{ }^{\circ} \mathrm{C}\right)$ Obtained at Slow $\left(2^{\circ} \mathrm{C} \mathrm{min}^{-1}\right)$ and High $\left(20^{\circ} \mathrm{C} \mathrm{min}{ }^{-1}\right)$ Heating Rates Corresponding to the First Mass Loss Stage for All Polymer Samples

\begin{tabular}{lcc}
\hline & \multicolumn{2}{c}{$\Phi\left({ }^{\circ} \mathrm{C} \mathrm{min^{-1 } )}\right.$} \\
\cline { 2 - 3 } Sample & 2 & 20 \\
\hline LRPL & 258.8 & 294.6 \\
LRPM & 258.5 & 292.6 \\
LRPH & 265.2 & 297.6 \\
FRPL & 245.9 & 280.7 \\
FRPM & 250.8 & 282.3 \\
FRPH & 250.5 & 287.3 \\
\hline
\end{tabular}

ratios chain transfer to propagation ending in low-molecular weight polymers. The temperature increase is also responsible for higher occurrence of side reactions. This is the reason why the thermal stability of this polymer increases with the molecular weight for the FRP. The mechanisms involved in the formation of the structural defects during the free radical polymerization of VCM were extensively studied over the last decades. ${ }^{15,16}$ On the other hand, due to the absence of side reactions, in the LRP approach the molecular weight is completely controlled by the ratio monomer/initiator. Previous experiences had shown that in the range of $21-42^{\circ} \mathrm{C}$, the polymer is free of structural defects. ${ }^{10}$ In this contribution, the PVC-LRP samples regardless of the molecular weight were prepared at $35^{\circ} \mathrm{C}$.

The thermal decomposition of the polymeric samples under study was investigated in nonisothermal conditions at 2 and $20^{\circ} \mathrm{C} \mathrm{min}{ }^{-1}$. Figure 5 compares typical thermoanalytical curves for LRP- and FRPPVC samples, collected at $20^{\circ} \mathrm{C} \mathrm{min}{ }^{-1}$ (the thermal behavior at $2^{\circ} \mathrm{C} \mathrm{min}^{-1}$ is qualitatively identical to those in Fig. 5). Both polymeric samples exhibit the expected two-step degradation behavior. The first corresponds to the hydrogen chloride elimination, being the second ascribable to thermal degradation of the remaining polymer. The temperature at which the decomposition starts can be used as a measure of the thermal stability of the PVC samples. Table IV resumes the extrapolated onset temperatures $\left(T_{\text {on }}\right)$ corresponding to the first mass loss stage (dehydrochlorination) obtained from all thermoanalytical measurements performed.

Besides the expected increasing in $T_{\text {on }}$ with the heating rate, the values in Table IV suggest that, at each heating rate, the only trend that can be detected is a shift in $T_{\text {on }}$ toward higher temperatures on going from one to another MW PVC samples extremes. For the PVC-LRP grouping, the shifts are $\sim 6.4^{\circ} \mathrm{C}$ and $3.0^{\circ} \mathrm{C}$ at 2 and $20^{\circ} \mathrm{C} \mathrm{min}{ }^{-1}$, respectively, whereas for the PVC-FRP samples the found values are $\sim 4.6$ and $6.5^{\circ} \mathrm{C}$. But the results summarized in Table IV reveal a very interesting feature. It is clear that the PVC samples prepared by LRP possess higher onset temperatures for degradation regardless the range of molecular weight or heating rate considered. It is noteworthy that the sample LRPL presents a higher onset temperature than FRPH sample for both heating rates considered. These results prove the remarkable thermal stability of the LMW weight PVC prepared by LRP, in contrast to the commercial products prepared by FRP, where the LMW PVC samples present very poor thermal stabilities. Apart from the high thermal stability of the LRPL sample, it should be stressed that this sample has very low viscosity, which turn it suitable for the applications that require low melt viscosities.

Figure 6 presents the plots of $\alpha$ and $d \alpha / d t$ as a function of temperature obtained from the TG curves after normalization (dehydrochlorination stage only), for all PVC samples. These plots allow us to uncover interesting differences in the hydrogen chloride elimination step, not revealed by the overview of the thermal behavior of PVC samples previously shown (Fig. 5). Even within the limits imposed by the macroscopic nature of the TA curves, it is possible to infer from these results the existence of quite different dehydrochlorination processes in LRP- and FRPPVC samples.

An essentially unique overall step (macroscopically speaking) within the temperature range $200-350^{\circ} \mathrm{C}$ (runs at $5^{\circ} \mathrm{C} \mathrm{min}^{-1}$ ) is observed in the decomposition of LRP-PVC samples. This contrasts with the two overall steps clearly identified in the decomposition FRP-PVC samples in the same temperature range.

These trends are not substantially changed by the heating rate. The particular physical characteristics of the samples (e.g., particle size distribution) are not enough to justify the observed differences, which thus would be a manifestation of substantial structural differences in LRP- and FRP-PVC samples. These findings suggest that the kinetics and mechanisms of the thermal dehydrochlorination process may not be a thoroughly covered topic.

\section{CONCLUSIONS}

In this work, it is demonstrated that the advantage of the LRP methods applied to the VCM polymerization in terms of thermal stability. Contrarily to the conventional method, where the reaction temperature dictates the final molecular weight, in the LRP approach this parameter is defined by the ratio monomer/initiator. This suggests that it is now possible to prepare PVC polymers with wide range molecular weight and the absence of structure defects that ultimately define the thermal stability of the polymers. The results observed suggested the possibility 

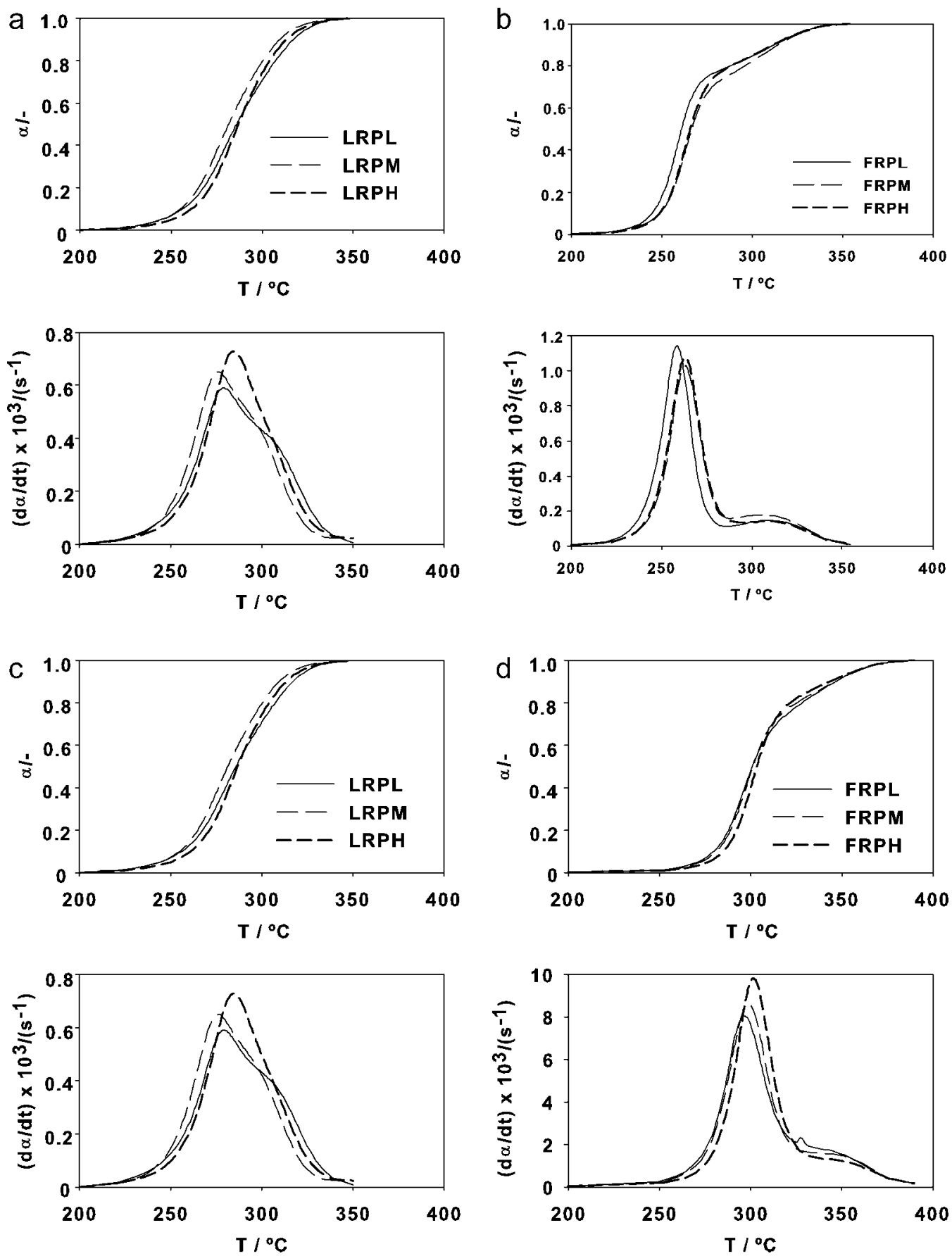

Figure 6 Normalized (dehydrochlorination stage only) mass loss $(\alpha)$ and corresponding time rate $(d \alpha / d t)$ as a function of temperature for all polymeric samples studied under the indicated heating rates: (a) LRP $2^{\circ} \mathrm{C} \min ^{-1}$; (b) $\mathrm{FRP} 2{ }^{\circ} \mathrm{C}$ min ${ }^{-1}$; (c) LRP $20^{\circ} \mathrm{C} \mathrm{min}{ }^{-1}$; and (d) FRP $20^{\circ} \mathrm{C} \mathrm{min}^{-1}$.

to prepare a low-viscosity PVC polymer with outstanding thermal stability. This feature of the lowmolecular weight PVC polymers prepared by LRP could be extremely interesting to enlarge the range of application of the PVC in specialty markets. Another important feature of these new products could be low requirement for stabilizers. In the context, an evaluation of the stabilization effect of the commercial stabilizer systems in regard to the
PVC-LRP and its comparison with the stability effect in the PVC-FRP samples would be extremely important.

The authors are deeply grateful to CIRES SA for providing the necessary conditions to prepare the PVC-CRP samples at the manufacture site. A special thanks to Eng. Pedro Gonçalves for his support and complete availability to discuss scientific and technical issues with us. 


\section{References}

1. Matyjaszewski, K.; Nakagawa, Y.; Jasieczek, C. B. Macromolecules 1998, 31, 1535.

2. Fuji, Y.; Ando, T.; Kamigaito, M.; Sawamoto, M. Macromolecules 2002, 35, 2949.

3. Farcet, C.; Charleux, B.; Pirri, R. Macromolecules 2001, 34, 3823 .

4. Georges, M. K.; Lukkarila, J. L.; Szkurhan, A. R. Macromolecules 2004, 37, 1297.

5. Chiefari, J; Chong, Y. K.; Ercole, F.; Krstina, J.; Jeffery, J; Le, T. P. T.; Mayadunne, R. T. A.; Meijs, G. F.; Moad, C. L.; Moas, G.; Rizzardo, E.; Thang, S. H. Macromolecules 1998, 31, 5559.

6. Percec, V.; Guliashvili, T.; Popov, A. V.; Ramirez-Castillo, E. J Polym Sci Part A: Polym Chem 2005, 43, 1478.

7. Percec, V.; Guliashvili, T.; Popov, A. V. J Polym Sci Part A: Polym Chem 2005, 43, 1948.

8. Percec, V.; Ramirez-Castillo, E.; Popov, A. V.; Hinojosa-Falcon, L. A.; Guliashvili, T. J Polym Sci Part A: Polym Chem 2005, 43, 2178.

9. Percec, V.; Popov, A. V.; Ramirez-Castillo, E.; Weichold, O. J Polym Sci Part A: Polym Chem 2003, 41, 3283.

10. Percec, V.; Popov, A. V.; Ramirez-Castillo, E.; Coelho, J. F. J.; Hinojosa-Falcon, L. A. J Polym Sci Part A: Polym Chem 2004, 42, 6267.

11. Percec, V.; Popov, A. V.; Ramirez-Castillo, E.; Weichold, O. J Polym Sci Part A: Polym Chem 2004, 42, 6364.

12. Coelho, J. F. J. New technologies for homopolymerization and copolymerization of vinyl chloride, Doctoral Thesis, University of Coimbra, Coimbra, 2006.
13. Percec, V.; Popov, A. V. J. Polym Sci Part A: Polym Chem 2005, 43, 1255.

14. Percec, V.; Guliashvili, T.; Popov, A. V.; Ramirez-Castillo, E.; Coelho, J. F. J.; Hinojosa-Falcon, L. A. J Polym Sci Part A: Polym Chem 2005, 43, 1649.

15. Starnes, W. H. J Polym Sci Part A: Polym Chem 2005, 43, 2451.

16. Starnes, W. H. J Prog Polym Sci 2002, 27, 2133.

17. Starnes, W. H. J; Chung, H.; Wojciechowski, B. J.; Skillicorn, D. E.; Benedikt, G. M. Polym Durabil Adv Chem Ser 1996, 249, 3.

18. Starnes, W. H. J; Wojciechowski, B. J.; Chung, H.; Benedikt, G. M.; Park, G. S.; Saremi, A. H. Macromolecules 1995, 28, 945.

19. Stockland, R. S.; Jordan, R. F. J Amer Chem Soc 2000, 122, 6315.

20. Stockland, R. A.; Foley, S. R.; Jordan, R. F. J Amer Chem Soc 2003, 125, 796.

21. Endo, K.; Saitoh, M. J Polym Sci Part A: Polym Chem 2003, 41, 248.

22. Wannemacher, T.; Braun, D.; Pfaendner, R. Macromol Symp 2003, 202, 11.

23. Coelho, J. F. J.; Gonc alves, P. M. F. O.; Miranda, D.; Gil, M. H. Eur Polym J 2006, 42, 751.

24. Coelho, J F. J; Silva, A. M. F. P.; Popov, A. V.; Percec, V.; Abreu, M. V.; Goncalves, P. M. O. F.; Gil, M. H. J Polym Sci Part A: Polym Chem 2006, 44, 2809.

25. Butters, G. Particle Nature of PVC; Applied Science Publishers: London, 1982.

26. Salamone, J., Ed.; Polymeric Materials Encyclopedia; CRC Press: Boca Raton, 1996; Vol. 9. 